\title{
Relative role of sediment entrainments on log-law parameters of longitudinal velocity distributions in mobile bed flows
}

\author{
Pritam Malakar*, Ratul Das \\ Civil Engineering Department, National Institute of Technology Agartala, Agartala-799046, India. E-mail: ratulnitagartala@gmail.com \\ * Corresponding author. Tel.: +91 8131054353. E-mail: pritam.its@gmail.com
}

\begin{abstract}
In alluvial channel, the non-cohesive bed particles are frequently accelerated by the flows and there has been an inconclusive debate on the deviations of logarithmic law parameters that demonstrate the velocity distributions in flows. Present study aims to elucidate the current knowledge of overwhelming theoretical and experimental evidences in this regard within the scope of near-bed turbulent flow characteristics. The study was conducted in two folds collecting instantaneous velocity of flow over a rigid sand bed under clear water flow conditions and compared to those over mobile sand beds under equilibrium bed-load. Results corroborated additional support to confirm the upward shifting of zero-velocity level in mobile bed flows. Most importantly, the conventional value of von Kármán coefficient significantly deviates in mobile bed flows compared to those in rigid sand bed. Also, the frictional velocity obtained from the bed slope consistently differs to those obtained from the Reynolds shear stress (RSS) distributions owing to transfer of stress aliquot to the bed particles. The mechanism is well demonstrated with the energy-momentum transfer within the framework of energy budget concept which shows near-bed negative pressure energy diffusion rates with increasing turbulence production in mobile bed flows.
\end{abstract}

Keywords: Alluvial channel; Energy budget; Hydrodynamics; Mobile bed; Zero-velocity level.

\section{INTRODUCTION}

Flow-stream-bed interaction in alluvial channel is a classical problem as they produce many morphodynamical changes. In mobile bed stream, individual bed-particles remain in contact with the bed and set into motion as a part of bed-load as shown in Fig. 1. It is worth mentioning that the sediment entrainment is directly governed by the flow characteristics and impetus new light on the near-bed turbulent flow characteristics (Balachandar et al., 2001; Guo, 1998; Kironoto and Graf, 1994; Yang, 2010). In recent years, several publications have appeared on mobile bed hydraulics and the interaction of overlying flows with the bed load transport imposes challenge when it comes to quantify the relative role of sediment mobility on the near-bed flow fields (Best et al., 1997; Dey and Raikar, 2007; Gaudio et al., 2011; Gust and Southard, 1983; Song et al., 1994). Many researchers reported that during sediment entrainment and collisions bed-particles receive kinetic energy from the overlying flow resulting enhanced flow resistance (Calomino et al., 2004;
Owen, 1964; Smith and McLean, 1977; Song et al., 1998; Wang and Larsen, 1994). In contrast, other researchers showed that sediment entrainment and bed-load transport cause reduction of flow resistance with an increase of streamwise velocity (Carbonneau and Bergeron, 2000; Nikora and Goring, 2000). Present study is concerned with the impact of sediment mobility on the parameters of the formula that represent the mean velocity profiles in mobile bed flows. Traditionally, the streamwise velocity profile in the inner-layer of the flow $(z \leq 0.2 h$, where $z$ is the vertical coordinate and $h$ is the flow depth in the channel) can be fitted to the universal logarithmic law of wall (log-law) as:

$$
u^{+}=\frac{1}{\kappa} \ln \left(\frac{z^{\prime}}{z_{0}}\right)
$$

where, $u^{+}=$non-dimensional time averaged streamwise velocity, $\kappa=$ von Kármán coefficient, $z^{\prime}=$ function of displacement height $(\Delta z)$ above the zero velocity level $\left(z_{0}\right)$. Characterization

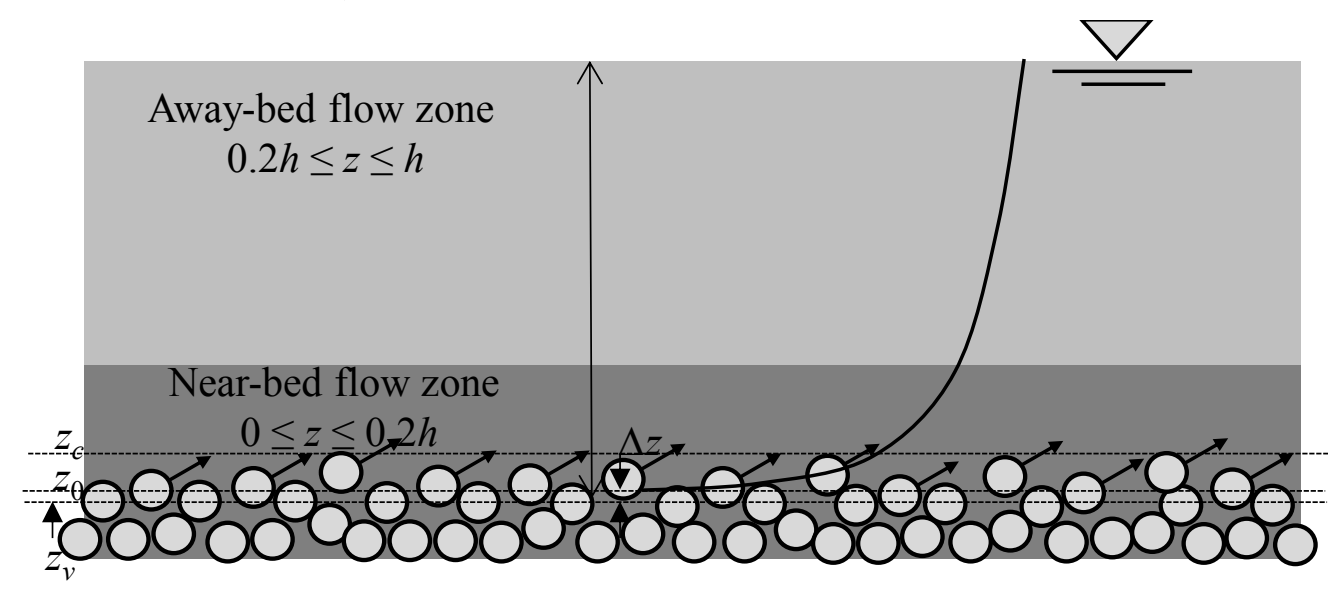

Fig. 1. Definition sketch of mobile bed flows: $z_{c}=$ crest level, $z_{0}=$ zero velocity level, $z_{v}=$ virtual bed level, $z=$ vertical distance, $h=$ flow depth. 
of $u^{+}$with $z_{0}$ and $\Delta z$ are very essential in order to fit the velocity profiles with logarithmic law of the wall. Since many decades the process of delineating $z_{0}$ has been largely studied in accordance with the assumptions charted in the definition of zero boundaries (Schlichting and Gersten, 1979). In general, the lower boundary of the inner flow region located $\Delta z$ above or below the definition boundary zero is considered as $z_{0}$ whereas, the vertical distance between $z_{0}$ and zero boundary indicate $\Delta z$. Some researchers argued that the zero plane indicate the lower limit of flow penetration depth below the crest level and there is no significant exchange of momentum occurs below the zero boundary line (Ferreira et al., 2012; Nikora et al., 2002). Secondly, another important parameter is the von Kármán coefficient $(\kappa)$ in the log-law of velocity profile and many researchers adopted the value as 0.41 irrespective of channel wall conditions (Kirkgoz and Ardiclioglu, 1997; Miguthanna et al., 2020). Importantly, some recent experimental studies reported significant deviations of $\kappa$ in mobile bed open channel flows and found to be in the range of 0.28 to 0.34 (Dey and Raikar, 2007; Gaudio et al., 2010; Nikora and Goring, 2000). A short review in this regard is presented in Fig. 2. The results provide confirmatory evidence on the influence of sediment mobility on $\kappa$. It is argued that the enhancement in velocity gradients and near bed turbulence intensity owing to sediment mobility leads to the reduction in $\kappa$. Further, the assessment of frictional velocity $(u *)$ to plot the log-law profile is crucial as it correlates the sediment mobility to the flow characteristics. In mobile bed stream, it is worth noting that the transports of grains are governed by the momentum extracted from the flow. Hence, a significant portion of the flow energy transfers to turbulence through turbulent energy generation resulting large vortices during bed-load transport and associated to the RSS aliquot transferred to the bed particles (Grass, 1970; YeganehBakhtiary et al., 2009). The momentum extracted from the flow and energy dissipation can be well presented through the local balance of turbulent kinetic energy (TKE) budget components. The TKE-budget analyses are already demonstrated by many authors in the domain of atmospheric boundary layers and hydraulically smooth, transitionally rough and flows over vegetated canopies (Balachandar and Bhuiyan, 2007; Dey et al., 2012; Mignot et al. 2009; Raupach and Shaw, 1982). Recent growth in the volume of research offers significant impetus on TKE-budget concept for assessing especially the pressure energy diffusion rates over the mobile bed which cannot be measured directly. Therefore, the present laboratory work is devoted to clarify how sediment mobility during bed-load transport influences the parameters of the time-averaged velocity distributions and energy-moment exchange over a mobile sand bed. The paper is organized as follows: the experimental procedure and bed configuration is followed by a brief introduction. The results and discussions are described next. Finally, the summary and conclusions are given.

\section{EXPERIMENTAL PROCEDURE}

A rectangular open-channel of $15.0 \mathrm{~m}$ length was used to perform the laboratory experiments as shown in Fig. 3 (a). The width and height of the channel was $0.91 \mathrm{~m}$ and $0.80 \mathrm{~m}$, respectively. Both sides of the channel were made of glass walls for visual observations. Uniform grains of sand $\left(d_{50}=0.65 \mathrm{~mm}\right)$ was glued on the flume bottom with cement slurry for preparation of rigid sand bed having longitudinal bed-slopes $(S)$ of 0.1 and $0.075 \%$ (Fig. 3 b). All the tests were performed under uniform flow conditions. Three Vernier point gauges were used to check the uniform flow depth at different points in the flow. In mobile bed experimental runs, sediment feeding was imposed into the flow at the upstream end maintaining dynamic equilibrium conditions (Fig. 3c). In each bed, three tests were conducted with the flow rates of $0.1,0.07$ and $0.055 \mathrm{~m}^{3} / \mathrm{s}$. The mean velocity $(U)$, flow Reynolds number $\left(R_{e}\right)$, flow Froude number $(F)$ and bed-load transport rate $\left(g_{b}\right)$ varied in the following ranges: $0.48 \mathrm{~m} / \mathrm{s} \leq U \leq 0.67 \mathrm{~m} / \mathrm{s}, 1.8 \times 10^{5} \leq R_{e} \leq 3.4 \times$ $10^{5}, 0.44 \leq F \leq 0.53$ and $1.03 \times 10^{-2} \mathrm{~kg} /(\mathrm{ms}) \leq g_{b} \leq 3.28 \times 10^{-2}$ $\mathrm{kg} /(\mathrm{ms})$. The experimental details can be found in Malakar et al. (2020). In order to achieve dynamic equilibrium conditions, the sediment transport rate was initially quantified by collecting the transported grains in a sediment collector installed at downstream. During the tests either deposition or erosion was observed. After finalising the desirable flow conditions that enables sediments rolling over the bed, the velocity measurements were undertaken along the vertical line at the mid cross-section of the flume. An acoustic Doppler velocimeter (ADV) of

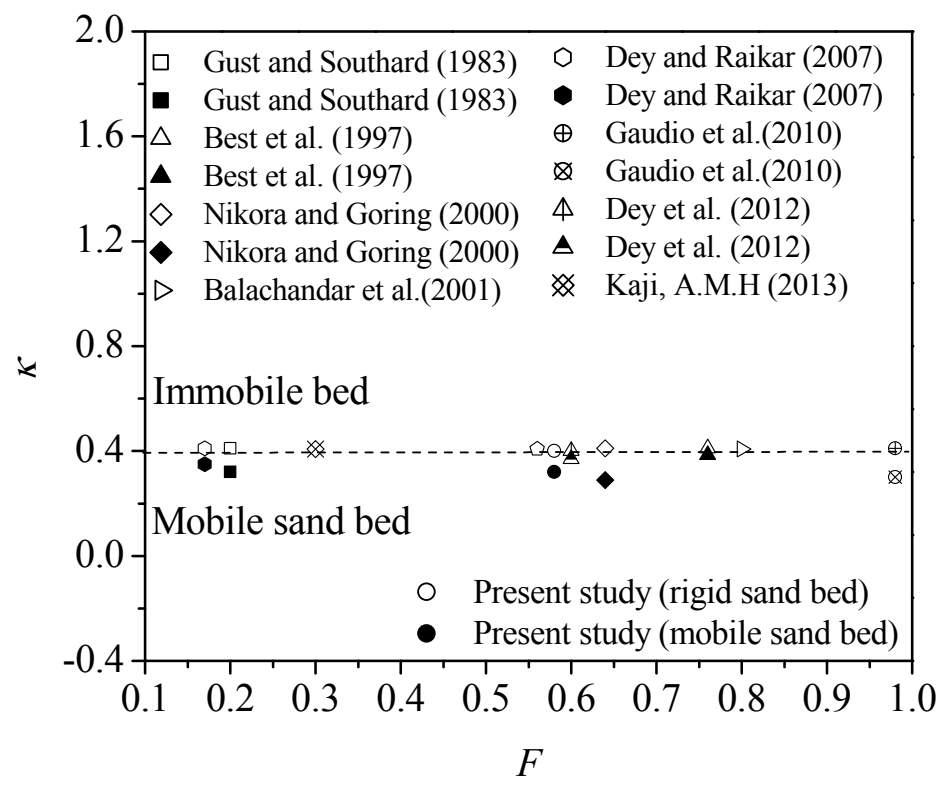

Fig. 2. A review of von Kármán coefficient, $\kappa$. 


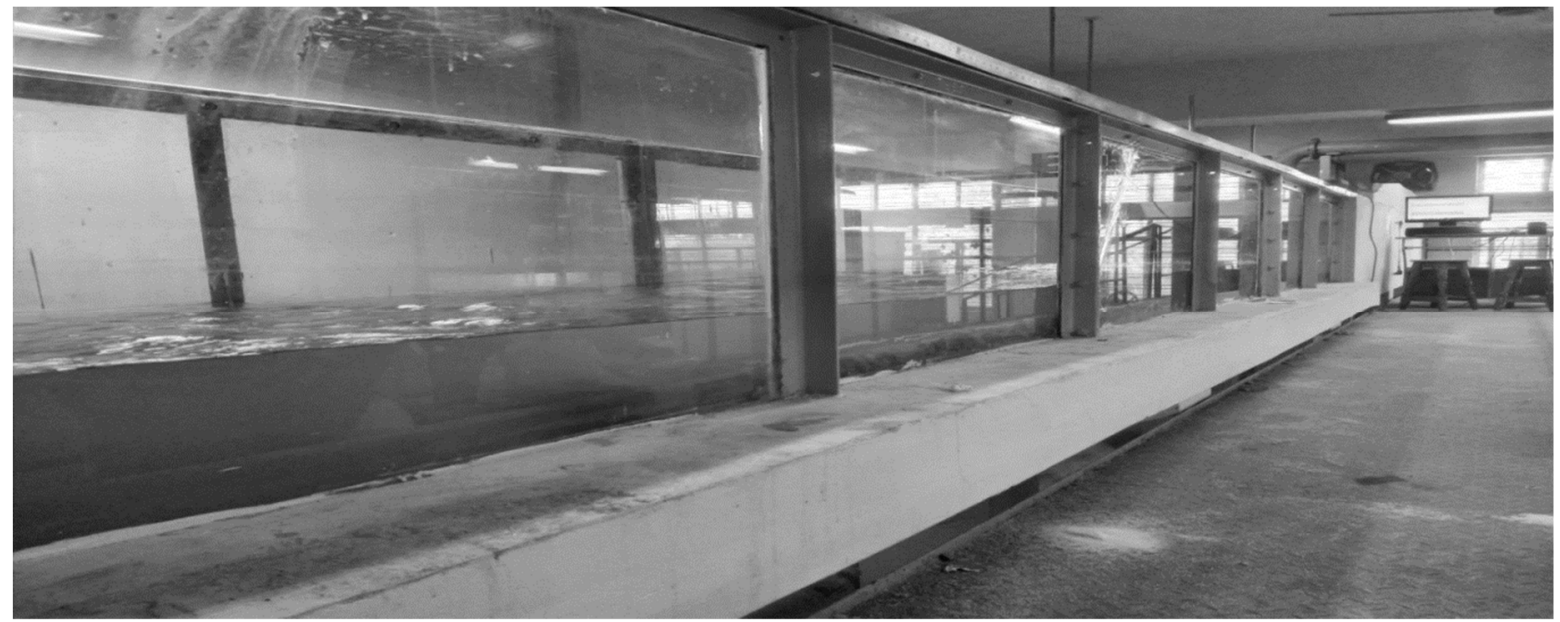

(a)

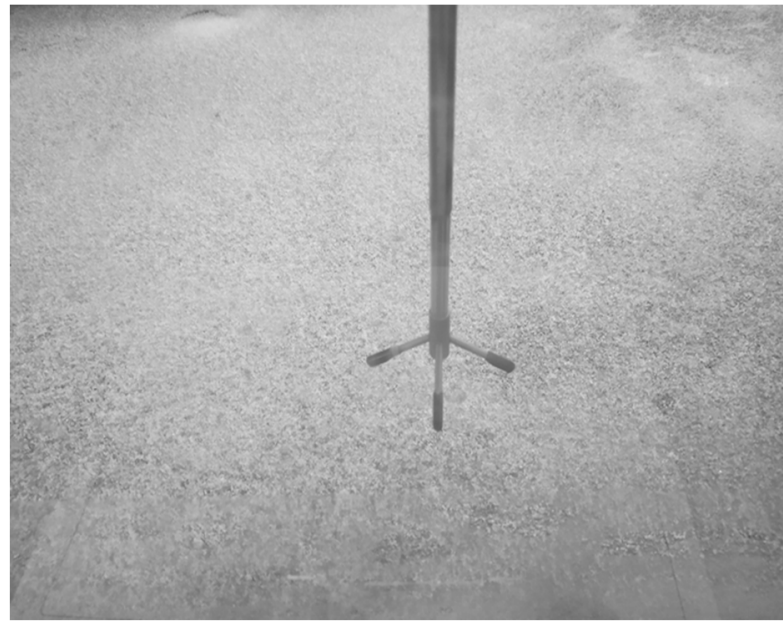

(b)

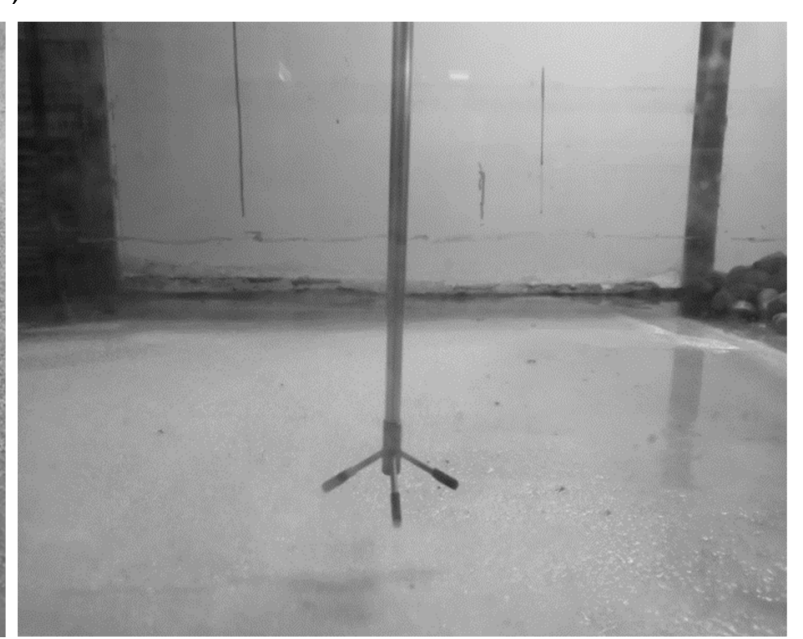

(c)

Fig. 3. (a) Experimental setup (b) rigid sand bed and (c) mobile sand bed.

$10 \mathrm{MHz}$ frequency was used to measure the velocity with 100 $\mathrm{Hz}$ sampling rate. The sampling volume was cylindrical that had $6 \mathrm{~mm}$ diameter and $1-4 \mathrm{~mm}$ adjustable height. The acoustic sensor comprises of one transmitting transducer and four receiving transducers. Addition of a fourth receiver improves turbulence measurements and provides redundancy. As the measuring location was $5 \mathrm{~cm}$ below the probe, there was no significant influence of the instrument on the measured data.

The signal-noise ratio (SNR) was maintained equal to or above 15. The ADV was fixed $8 \mathrm{~m}$ away from the flume inlet and at the mid cross-section of flume. Instantaneous velocity for 180 s was captured along the vertical direction of flow depth at $1 \mathrm{~mm}$ interval. The longitudinal direction of flow is considered as $x$-axis, whereas transverse and vertical directions are considered as $y$ and $z$-axis, respectively. Therefore, the measuring location has coordinates $(0,0, z)$. In all the test runs, the flume width to flow depth ratio was more than 5 in order to avoid any secondary current effects induced by the side-glass walls. The measured data were filtered with a spike removal algorithm (Goring and Nikora, 2002).

\section{RESULTS AND DISCUSSION \\ Zero velocity level (zo) and law of the wall:}

The vertical distributions of dimensionless time-averaged streamwise velocity, $u^{+}$are shown in Figure 4 . In the present study, the time-averaged streamwise velocity $(\bar{u})$ is normal- ized by $u *$ whereas, the vertical coordinates $(z)$ is normalized by $d_{50}$ which enable us to fit data with log-law of velocity distributions as (Dey et al., 2012):

$$
\frac{\bar{u}}{u_{*}}=\frac{1}{\kappa} \ln \left(\frac{z / d_{50}+\Delta z / d_{50}}{z_{0} / d_{50}}\right)
$$

where, $\bar{u} / u^{*}=u^{+}, z / d_{50}=z^{+}, \Delta z / d_{50}=\Delta z^{+}$and $z_{0} / d_{50}=z_{0}^{+}$. A comparative study of log-law fittings of the velocity profiles over both the test beds are illustrated in Fig. 4 (a, b, c) and Fig. 4 (d, e, f) for longitudinal bed slopes $(S)=0.1$ and $0.075 \%$, respectively. The $u^{+}$profiles obtained from both the slopes exhibit a similar trend and it is worth noting that the use of parameters from Table 1 for an individual run produces a very good matching between the experimental data and the log-law confirming the legitimacy of the findings. The assessment of $z_{0}^{+}$and $\Delta z^{+}$is a challenging task. $z_{0}$ is the height above virtual bed for which the estimated velocity is zero (Eq.1) whereas, it is very common to consider the virtual bed level at $0.25 d_{50}$ below the crest level of bed (Van Rijn, 1984). $z_{0}$ is directly governed by the size of sand grains that compose the bed and to our knowledge extensive works have been carried out by many authors pertaining to indirect assessment of this parameter as a function of geometric roughness scale, $k_{\mathrm{s}}$ and given as (Schlichting and Gersten, 1979) 


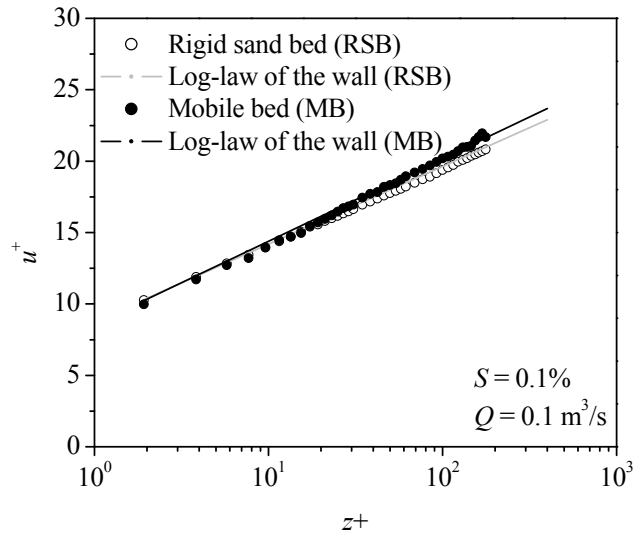

(a)

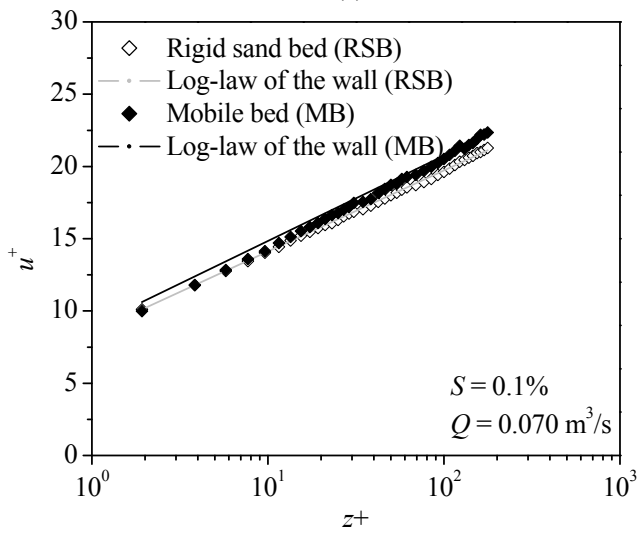

(b)

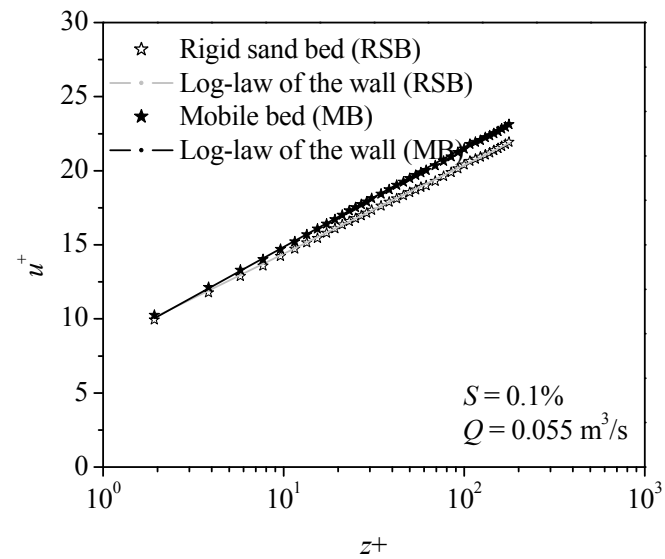

(c)

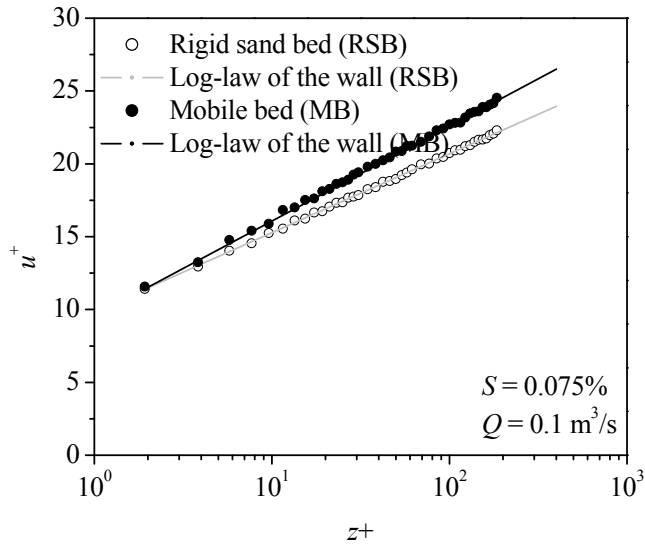

(d)

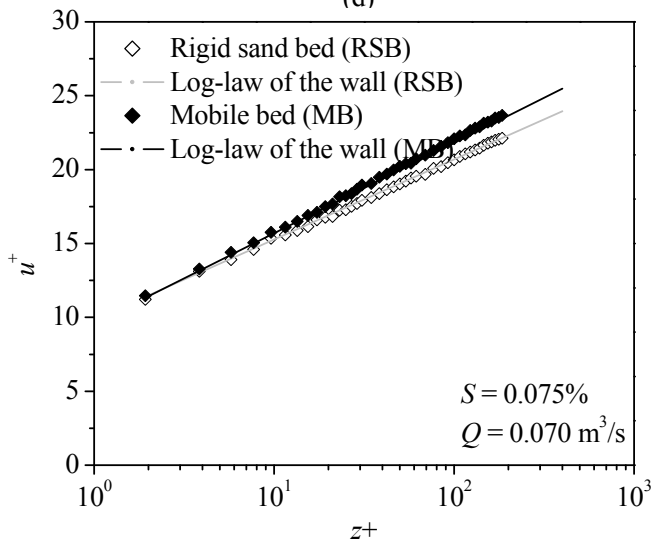

(e)

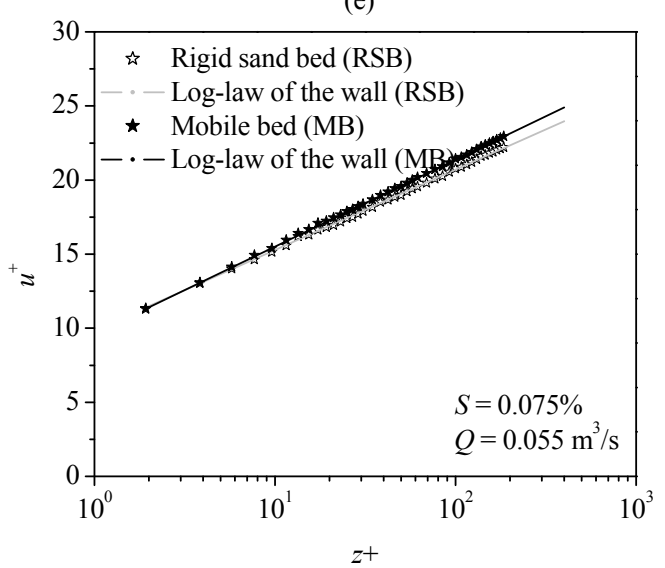

(f)

Fig. 4. Vertical distributions of dimensionless time-averaged streamwise velocity $\left(u^{+}\right)$(a, b, c) $S=0.1 \%$ and (d, e, f) $S=0.075 \%$.

Table 1. Measured Log-law parameters.

\begin{tabular}{|c|c|c|c|c|c|c|c|}
\hline Group & Tests & Test category & $u *_{s}$ & $u_{*_{\tau}}$ & $\kappa$ & $\Delta z^{+}$ & $z_{0}^{+}$ \\
\hline \multirow{6}{*}{$S=0.1 \%$} & \multirow[b]{2}{*}{ Test 1} & Rigid bed & 0.0343 & 0.0420 & 0.41 & 0.384 & 0.033 \\
\hline & & Mobile bed & 0.0343 & 0.0401 & 0.38 & 0.207 & 0.039 \\
\hline & \multirow[b]{2}{*}{ Test 2} & Rigid bed & 0.0316 & 0.0379 & 0.41 & 0.169 & 0.029 \\
\hline & & Mobile bed & 0.0316 & 0.0360 & 0.38 & 0.207 & 0.036 \\
\hline & \multirow[b]{2}{*}{ Test 3} & Rigid bed & 0.0295 & 0.0353 & 0.40 & 0.384 & 0.033 \\
\hline & & Mobile bed & 0.0295 & 0.0334 & 0.35 & 0.205 & 0.039 \\
\hline \multirow{6}{*}{$S=0.075 \%$} & \multirow[b]{2}{*}{ Test 1} & Rigid bed & 0.0306 & 0.0350 & 0.41 & 0.384 & 0.0215 \\
\hline & & Mobile bed & 0.0306 & 0.0316 & 0.34 & 0.184 & 0.040 \\
\hline & \multirow[b]{2}{*}{ Test 2} & Rigid bed & 0.0282 & 0.0304 & 0.41 & 0.385 & 0.0215 \\
\hline & & Mobile bed & 0.0282 & 0.0281 & 0.37 & 0.210 & 0.032 \\
\hline & \multirow[b]{2}{*}{ Test 3} & Rigid bed & 0.0268 & 0.0274 & 0.41 & 0.384 & 0.0218 \\
\hline & & Mobile bed & 0.0268 & 0.0264 & 0.38 & 0.215 & 0.027 \\
\hline
\end{tabular}

$S=$ streamwise bed slope, $u *_{s}=$ frictional velocity obtained from slope, $u *_{\tau}=$ frictional velocity obtained from RSS, $\kappa=$ von Kármán coefficient, $\Delta z^{+}=$nondimensional depth of virtual bed level, $z_{0}^{+}=$nondimensional depth of zero-velocity level 
$z_{0}=0.11 \frac{v}{u_{*}}$ for smooth flow $R_{*} \leq 5$

$z_{0}=0.11 \frac{v}{u_{*}}+0.033 k_{s}$ for transition flow $5<R_{*}<70$

$z_{0}=0.033 k_{s}$ for rough flow $R_{*} \geq 70$

where, $k_{s}$ is the Nikuradse equivalent sand roughness and $R *$ is the particle shear Reynolds number. As the primary focus of this study is to illustrate the effects of sediment mobility on different parameters of the formula that express the velocity distributions, estimation of $z_{0}^{+}$and $\Delta z^{+}$obtained from the measured velocity are preferred in comparison to aforementioned correlations. Therefore, we started with a trial value of $\Delta z^{+}=0$ for regression analysis of Eq. (2) and subsequent estimation of $\kappa$ and $z_{0}$. In the next step, $\Delta z^{+}$is increased at regular interval by a small magnitude and the values of $\kappa, \Delta z^{+}$are reestimated. The values of $\Delta z^{+}, \kappa$ and $\Delta z^{+}$correspond to the maximum regression coefficient $(R C)$ are considered for log-law fittings and the procedure is well defined with a flow chart in Fig. 5. The average values of $\Delta z^{+}=0.39, \kappa=0.413$ and $z_{0}{ }^{+}=$ 0.034 over the rigid sand beds under clear water conditions are compatible to those for the traditional log-law over any rough beds. In mobile-bed runs, the average values of $\Delta z^{+}=0.21, \kappa=$ 0.37 and $z 0^{+}=0.04$ are evaluated with some scatter around the average log-law curve as shown in Fig. 6a, b. A close observation of $z_{0}^{+}$reveal upward shifting of the virtual bed level in mobile bed experimental runs indicating enhanced zerovelocity levels owing to the fact of sediment entrainment into the flows. Secondly, majority of prior research has adopted $\kappa$ as 0.41 and it is contradictory to consider the traditional value of $\kappa$ for unrest conditions of bed particles as reported by many authors (Kironoto and Graf, 1994; Song et al., 1994). Nikora and Goring (2000) reported decreasing trend of $\kappa$ in mobile bed runs. In the present study, the value of $\kappa$ is assessed from the mixing-length, $l$ based on the similarity hypothesis followed by smooth curve fitting to the measured data. The values of $\kappa$ obtained for all the experimental runs are plotted in Figs. 6 (c, d). The slope of the linear portion demonstrate $\kappa=l / z$. In the inner-layer, all the data points over the rigid sand bed and mobile bed tests are found well clustered on a single band as shown in Fig. 6c, d. The experimental data plots are compared with the theoretical curves, $l / h=\kappa(z / h)(1-z / h)^{0.5}$ (Dey et al., 2012) and noted well in agreement. A closer insight to the data plots reveal deviations in gradient for mobile sand bed with respect to the rigid sand bed under clear water conditions. In mobile-bed conditions the values of $\kappa$ were evaluated smaller than those in clear-water flows.

\section{Frictional velocity $(u *)$ :}

A proper assessment of friction or shear velocity $\left(u^{*}\right)$ is very much essential in order to fit the measured velocity profile to log-law of the wall. Estimation of $u^{*}$ from the bed slope is very common and in many cases, the results obtained does not enable to insight the relative role of sediment entrainment on

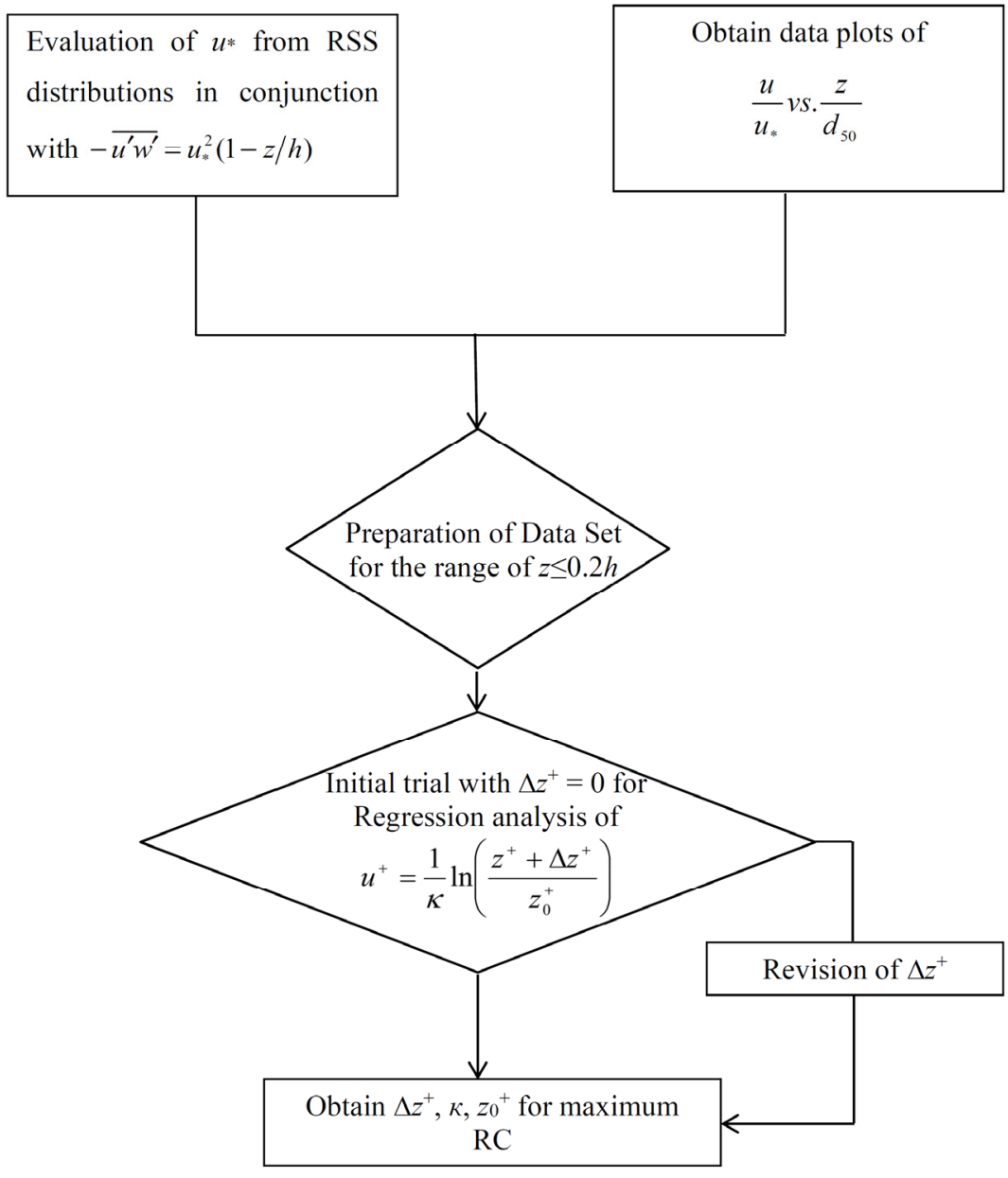

Fig. 5. Steps involved for estimation of displacement height. 


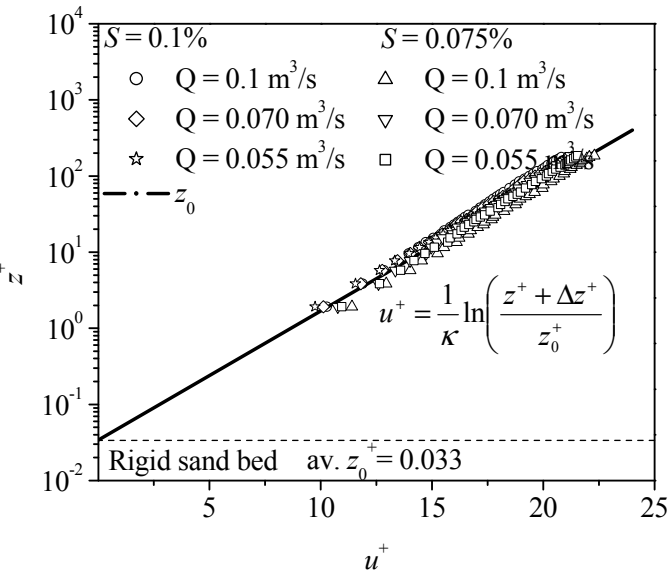

(a)

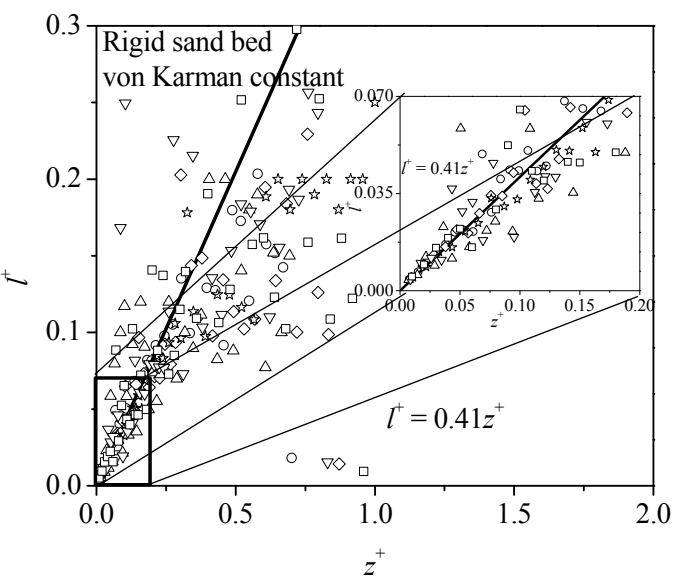

(c)

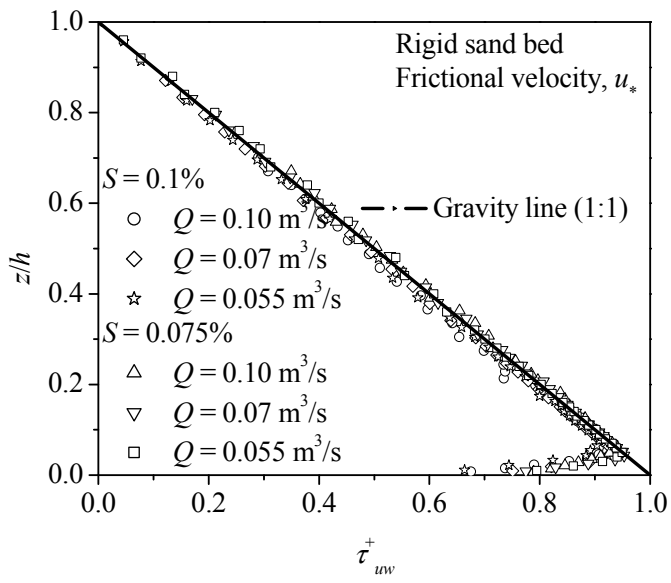

(e)

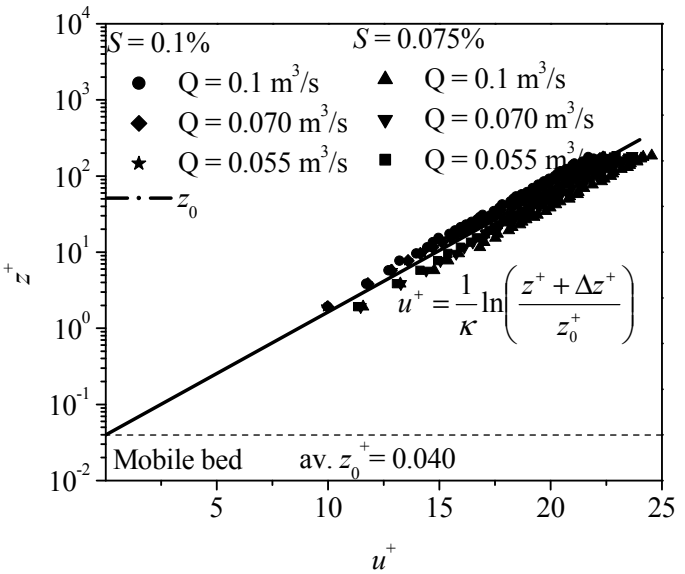

(b)

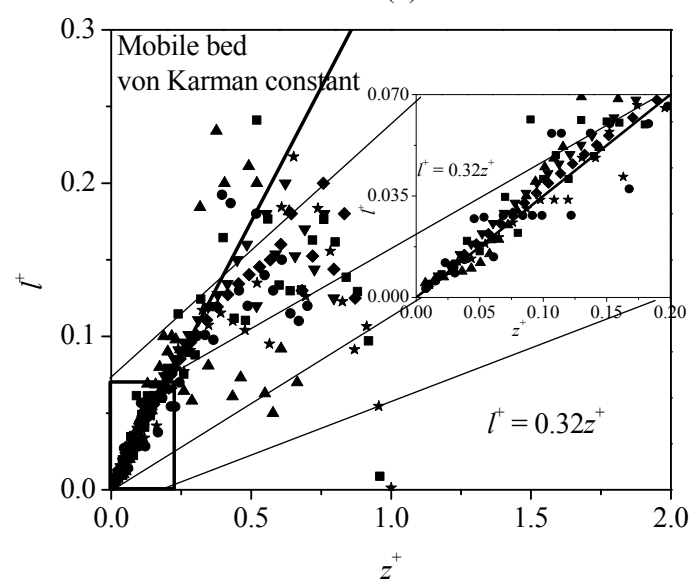

(d)

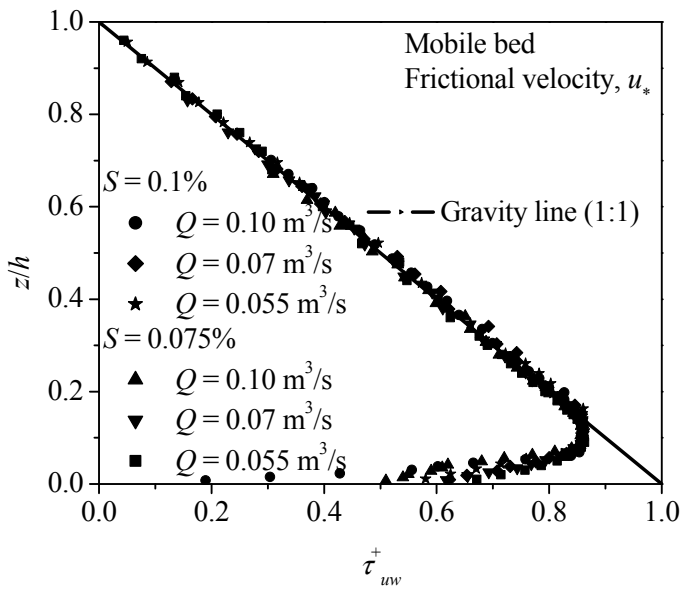

(f)

Fig. 6. Estimation of log-law parameters for rigid sand bed and mobile sand beds: (a, b) zero velocity level, $z_{0}$, (c, d) von Kármán constant, $\kappa$ and (e, f) frictional velocity, $u^{*}$

the flow characteristics in the inner-layer of flows. Therefore, $u *_{\tau}$ obtained from the RSS $\left(-\overline{u^{\prime} w^{\prime}}\right)$ distributions and extrapolating them to the bed as given below is preferred than those obtained from the bed slope $\left(u *_{s}\right)$.

$\tau_{t}=\left[1-\left(\frac{z}{h}\right)\right] \tau_{0}$

where, $\tau_{t}=$ total shear stress and $\tau_{0}=$ bed shear stress. In particular, the $\tau_{t}$ in mobile bed flows is balanced by the sum of bed shear stress associated to fluid $\left(\tau_{f}\right)$ and that of bed particles $\left(\tau_{b}\right)$ to overcome the frictional resistance. Therefore, the total bed shear stress balance yields

$$
\tau_{t}=\tau_{f}+\tau_{b}
$$

Table 1 presents the shear velocity obtained from the $u^{*}$ and $u^{*} \tau$ in both rigid and mobile bed runs. Importantly, it is noted that the shear velocity obtained from $u^{*}$ are consistently deviated from $u^{*} \tau$ in both the experimental runs. The vertical distribu- 
tions of nondimensional time-averaged RSS $\left(\tau_{u w}^{+}\right)$are shown in Figs. 6 (e, f). In the outer flow region, the measured data points are well matched with the so-called gravity line for both the cases. An excessive damping in the near-bed flow region over mobile sand bed is noticed compared to rigid sand bed. In order to address the deviations above, we interpret that during bed load transport individual grains are moved by the flows and the resistance at the contacts of bed particles decelerates them and the resulting wakes induces lower turbulence level in comparison to rigid sand beds. The results are quite convincing and the analysis of RSS distributions in mobile-bed streams shows that: 1) the decreasing turbulence level in mobile bed runs with respect to clear-water conditions produce a near-bed damping in RSS distributions; 2) the sand grains in motion in mobile bed tests extract momentum from the flow to overcome the bed resistance inducing a reduced level of RSS distributions in the near bed flow region.

\section{Performance tests of log-law parameters:}

The results obtained in the previous sections indicate several further questions on compatibility of the estimated parameters for the log-law fitting of velocity profiles. In order to address the questions properly, we present here the performance tests of the computed parameters by grouping into different categories as shown in Table 2. The deviations of $z_{0}{ }^{+}$with sediment mobility factor $(\theta)$ are importantly relevant in our study to interpret the results for both mobile and rigid sand bed tests. To demonstrate the correlation among the parameters, $\theta$ is considered as dependent variables while the other characteristic parameters as independent variables. Table 2 summarizes the Pearson correlation coefficient and significant $p$-value for each of the characteristic parameter given in Table 2. The criteria used to select the best regression model are based on: (a) coefficient of determination $P^{2}$ (b) mean square error and (c) Adjusted $P^{2}$ (Fig. 7a, b and c). Only characteristic parameters with weak correlation (between +0.3 and +0.7 or -0.3 and -0.7 ) and above were selected for regression analysis and given as

$$
\theta=\left[\begin{array}{l}
0.362\left(\frac{R}{d_{50}}\right)^{0.254}\left(\frac{z_{0}}{d_{50}}\right)^{0.815} \\
0.00652\left(\frac{R}{d_{50}}\right)^{0.644} \kappa^{0.7026} \\
1.305\left(\frac{R}{d_{50}}\right)^{0.658}\left(\frac{\Delta z}{d_{50}}\right)^{0.02639}
\end{array}\right]
$$

Here, it is pertinent to imply that the deviation of $z_{0}{ }^{+}$in the log-law profile and the virtual bed level with $\theta$ is a simple consequence of increasing bed thickness in mobile sand bed tests. It is apparent from the data plots of Fig. 8a that $z_{0}{ }^{+}$of the log-law profile is comparatively located deeper in rigid sand beds. The data plots of mobile and rigid sand bed experimental runs demonstrate the influence of the sediment mobility that associated to the upward shifting of the zero velocity level relative to the rigid sand bed. A closer insight of the data plots in Fig. 8a, b reveal $z_{0}{ }^{+}$and $\kappa$ as 0.03 and 0.41 , respectively in rigid sand bed under clear water condition and well in conformity with the customary values for the rough immobile bed given as $z_{0}{ }^{+}=0.033$ and $\kappa=0.41$ (Van Rijn 1984). In case of mobile bed tests, the average values are observed as $z_{0}{ }^{+}=0.04$ and $\kappa=0.37$ as shown in Fig. 8a, b. A short review of the results in mobile-bed flows indicate some degree of deviations and scatter with the average log-law profile. The slight increase of $z_{0}{ }^{+}$in mobile bed occurs owing to the fact of bed load transport whereas, the flow over immobile sand bed produce higher bed shear stress introducing larger form drag due to particles rigidity on the bed. The probable justification can be interpreted as gluing of grains to develop rigid sand surface otherwise they would be movable on the bed. In mobile bed tests $z_{0}{ }^{+}$are in the range of $0.04-0.045$ which configures an

Table 2. Regression analysis.

\begin{tabular}{|l|c|}
\hline Characteristic parameter & \begin{tabular}{c} 
Sediment mobility, $\theta=\frac{u_{*}^{2}}{\Delta g d_{50}}$ \\
\hline Particle diameter, $D_{*}=d_{50}\left(\Delta g / v^{2}\right)^{\frac{1}{3}}$
\end{tabular} \\
\hline Particle shear Reynolds number, $R_{*}=\frac{u_{*} d_{50}}{v}$ & $\begin{array}{c}0 \\
(p \text {-value }=1)\end{array}$ \\
\hline Zero velocity level, $\frac{z_{0}}{d_{50}}$ & $\begin{array}{c}0.999 \\
(p \text {-value }=0)\end{array}$ \\
\hline Displacement height, $\frac{\Delta z}{d_{50}}$ & $\begin{array}{c}0.752 \\
(p \text {-value }=0.084)\end{array}$ \\
\hline von Kármán constant, $\kappa$ & $\begin{array}{c}-0.272 \\
(p \text {-value }=0.6)\end{array}$ \\
\hline Degree of submergence, $\frac{R}{d_{50}}$ & $\begin{array}{c}0.122 \\
(p \text {-value }=0.81)\end{array}$ \\
\hline Bed slope, $S$ & $\begin{array}{c}0.485 \\
(p \text {-value }=0.32)\end{array}$ \\
\hline Aspect ratio, $\frac{h}{B}$ & $\begin{array}{c}0.698 \\
(p \text {-value }=0.122) \\
0.484 \\
(p \text {-value }=0.33)\end{array}$ \\
\hline
\end{tabular}

$d_{50}=$ median size of bed materials, $\Delta=s-1 ; s=$ relative density of sediment particles, $g=$ acceleration due to gravity, $v=$ kinematic viscosity of fluid, $R=$ hydraulic mean radius, $h=$ flow depth and $B=$ width of the channel 


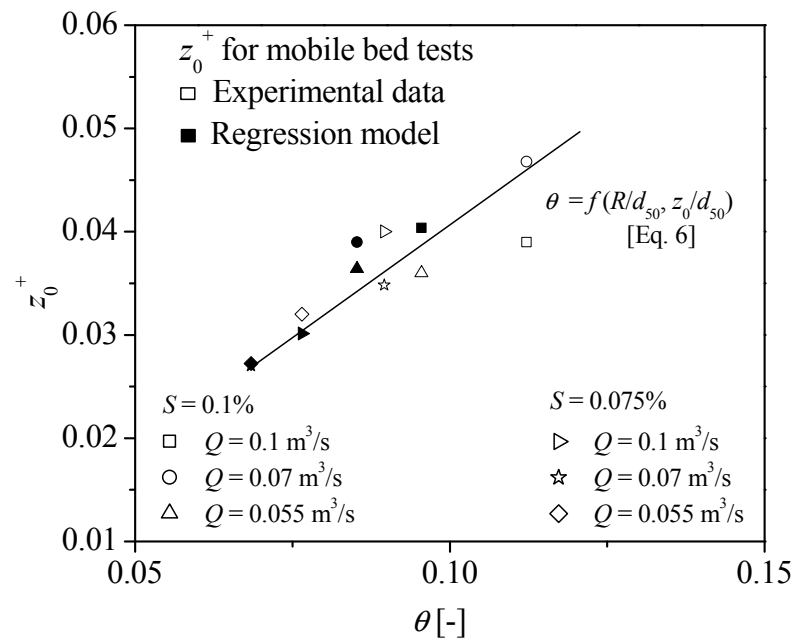

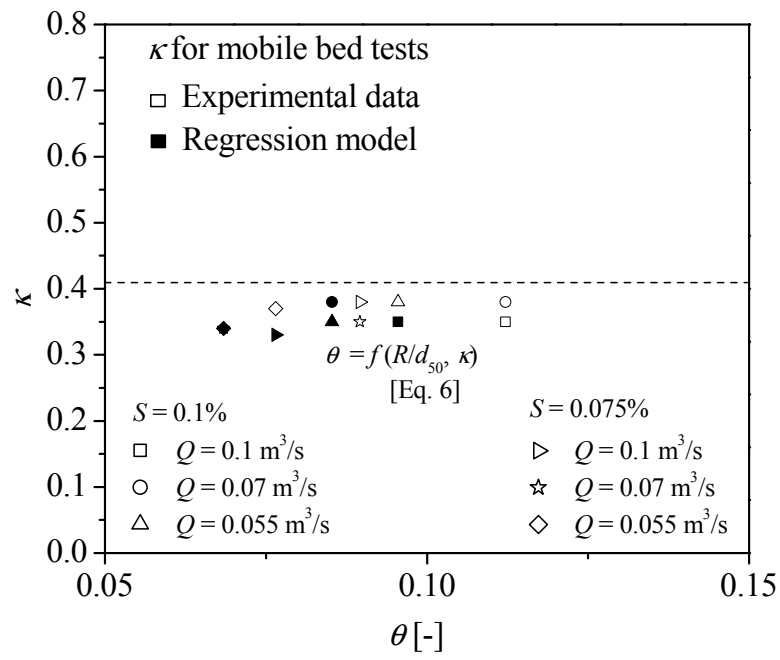

(b)

(a)

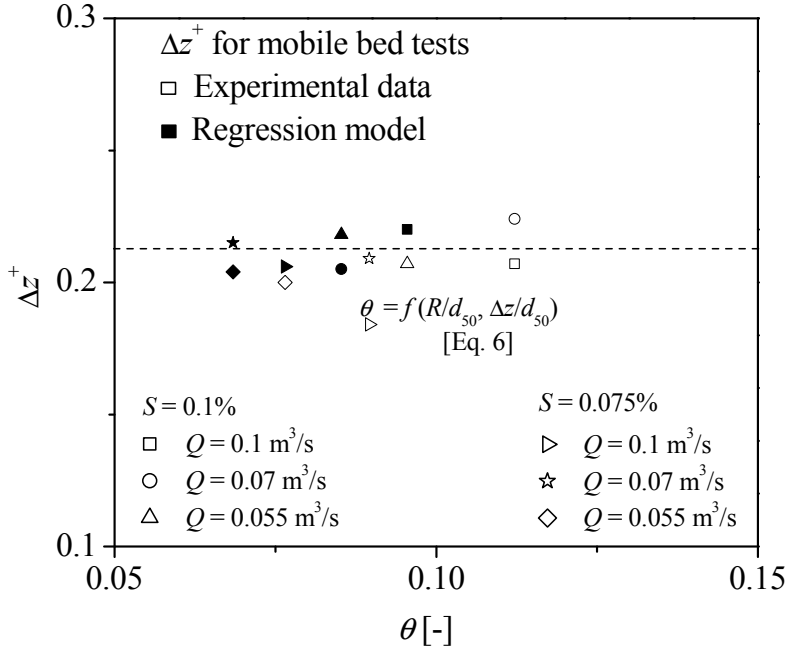

(c)

Fig. 7. Comparison of experimental data plots with Regression model: (a) variations of $\theta$ with $z_{0}$, (b) variations of $\theta$ with $\kappa$, (c) variations of $\theta$ with $\Delta z$

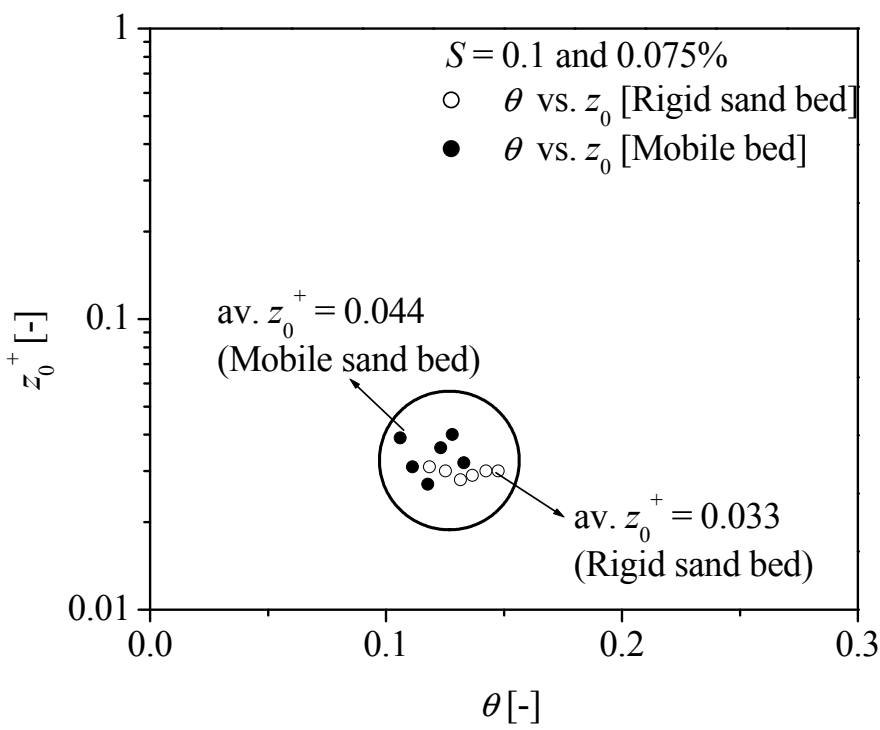

(a)

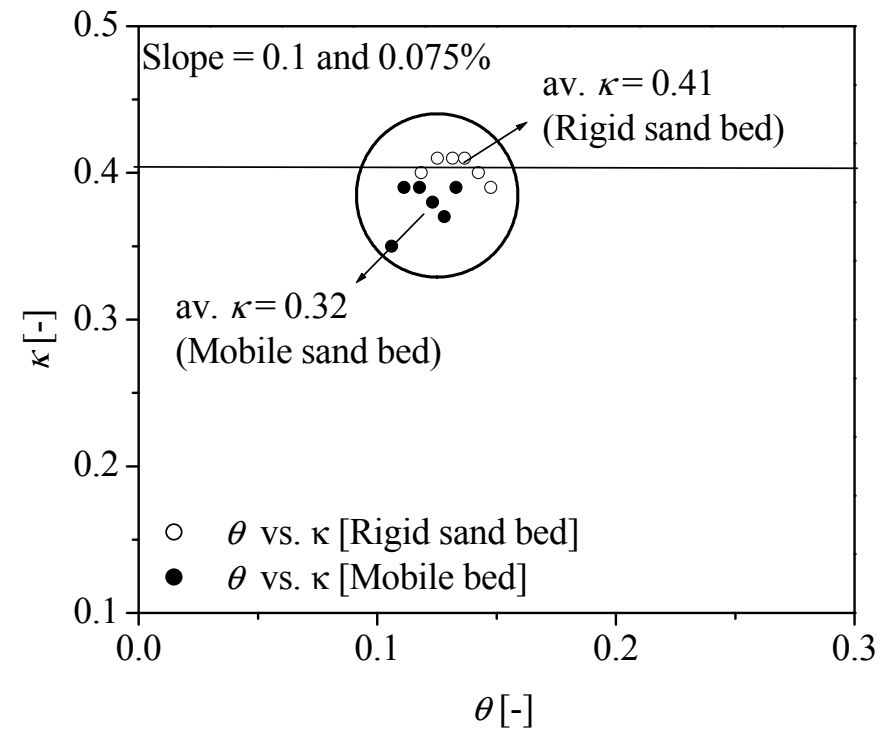

(b)

Fig. 8. (a) variations of $\theta$ with $z_{0}$ (b) variations of $\theta$ with $\kappa$ in mobile bed. 
increase of $z_{0}^{+}$compared to the immobile bed experiments. It can be concluded that this increase is related to larger bed thickness in mobile sand bed. This implies that $z_{0}{ }^{+}$is not a universal scale. Further to broaden our understanding, we interpret the obtained results in each case with three scenarios as presented in Fig. 9a, b and c. In the first case, $z_{0}^{+}$is set from the regression analysis of the measured velocity profile, $u *$ values are considered from RSS distributions and $\kappa$ is considered from mixing length theory (case1). In the second case, $z_{0}^{+}$is set from the correlations with equivalent sand roughness (Eq. 3), $u^{*}$ values are considered from RSS distributions, and $\kappa$ is considered from mixing length theory (case 2) and finally, for the third case, we set $z_{0}^{+}$from regression analysis of measured

(a)

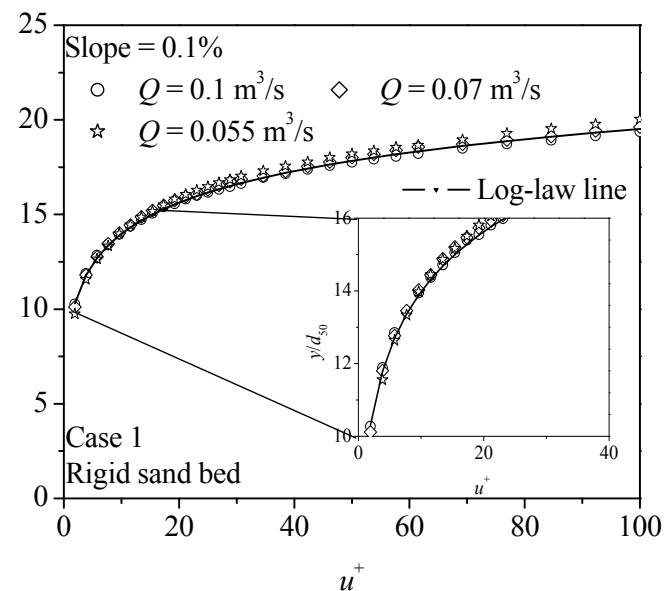

(b)

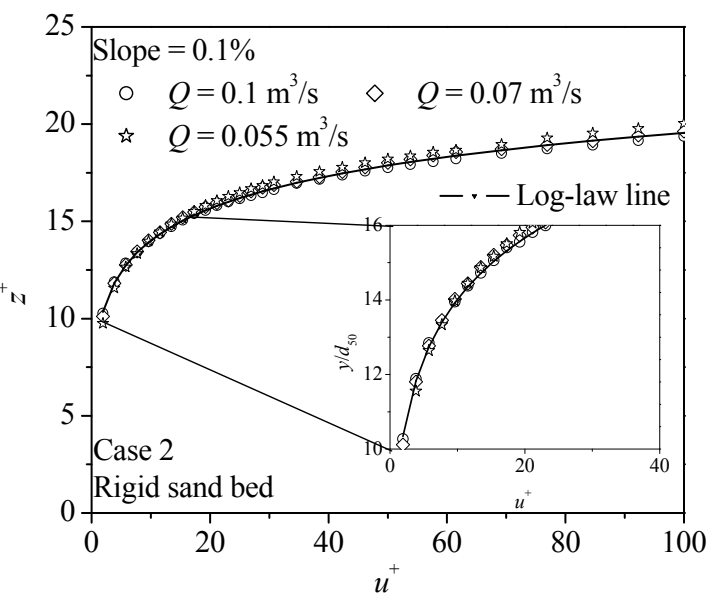

(c)

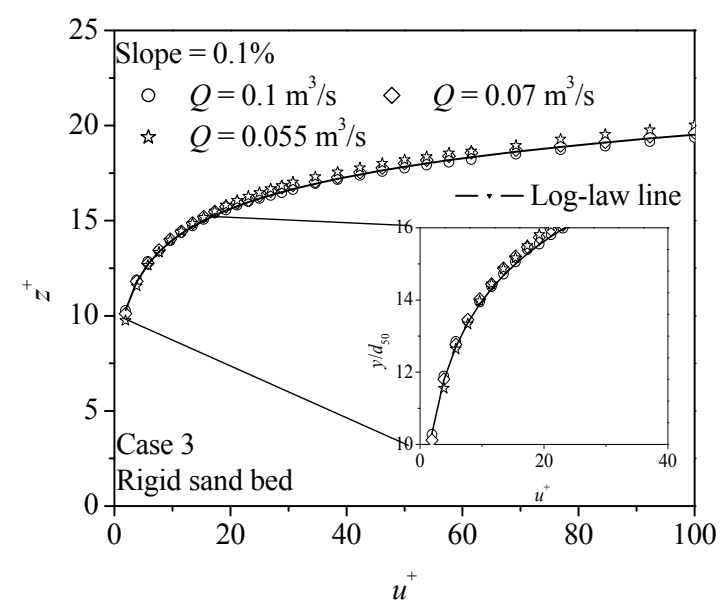

velocity profile, $u^{*}$ are considered from the RSS distributions and $\kappa$ is considered as universal constant $\approx 0.41$ (case 3 ). In all the cases, $\Delta z$ is defined as the depth of virtual bed level from the bed surface for which the velocity profile is logarithmic. For each scenario, the streamwise velocity profiles are shown in Fig. 9a, b and c. Comparison of the data plots over mobile sand bed for all the three cases (Fig. 9) reveal that the case 1 for which $z_{0}{ }^{+}$is computed from the maximum regression coefficient, $\kappa$ from the mixing length and $u^{*}$ from the RSS distributions are well in conformity to the logarithmic law of walls. On the other hand, the frictional velocity obtained from the bed slope $\left(u^{*}\right)$ and $\kappa$ as 0.41 are applicable to rigid sand bed under clear water conditions only.
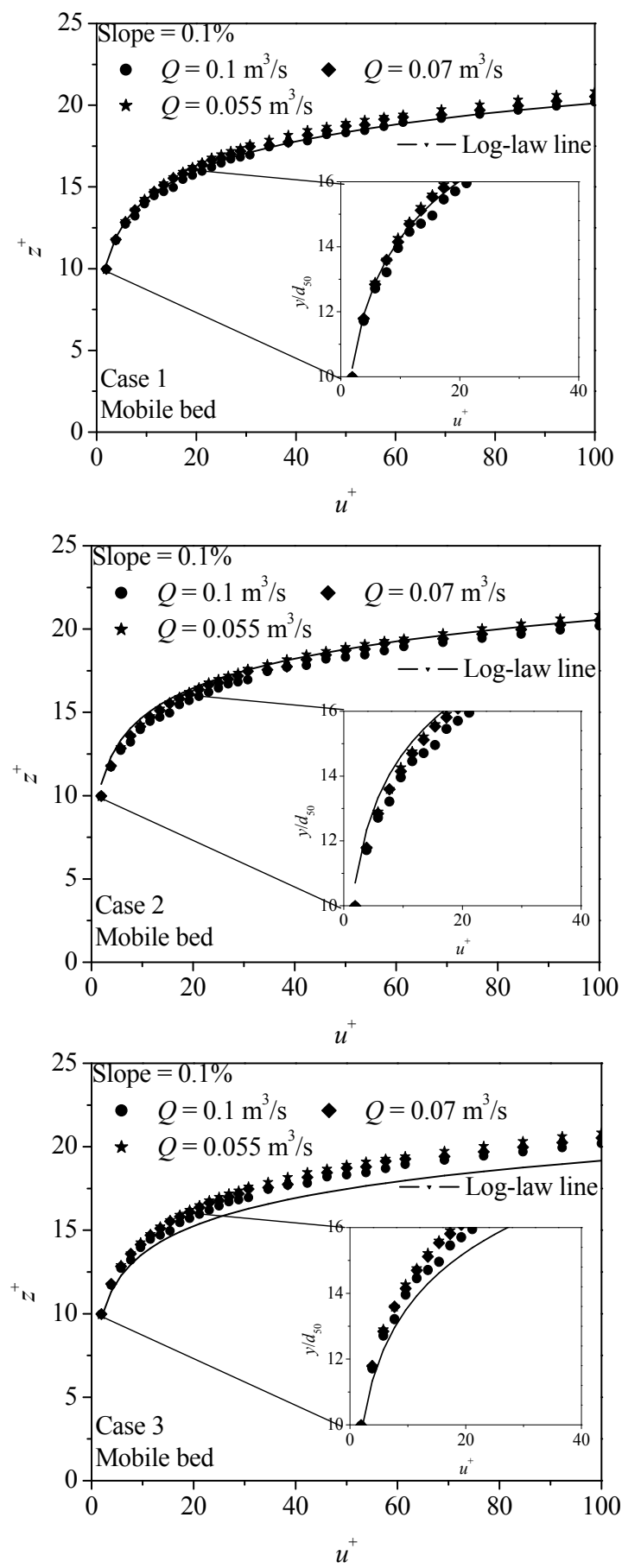

Fig. 9. Fittings of longitudinal velocity profiles with log-law of the walls for rigid and mobile sand beds: (a) case 1, (b) case 2 and (c) case 3 . 


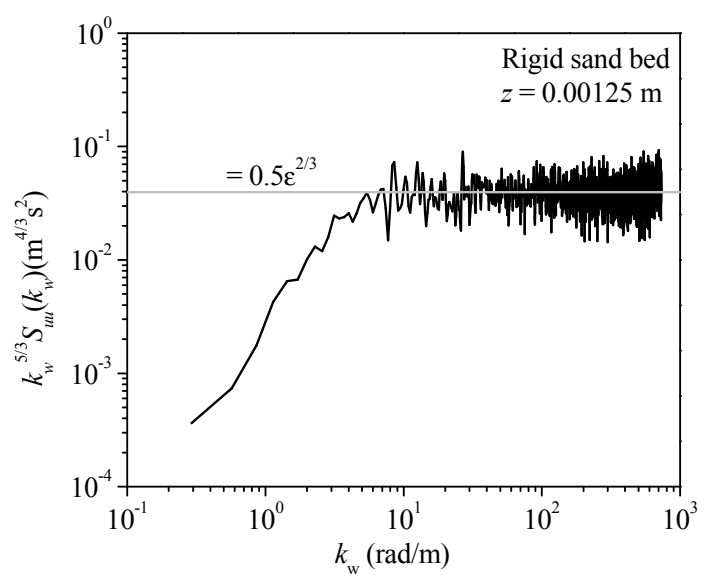

(a)

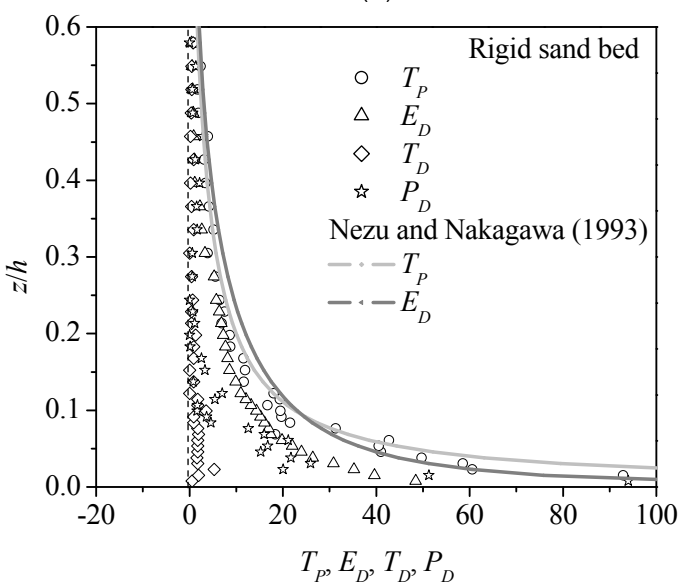

(c)

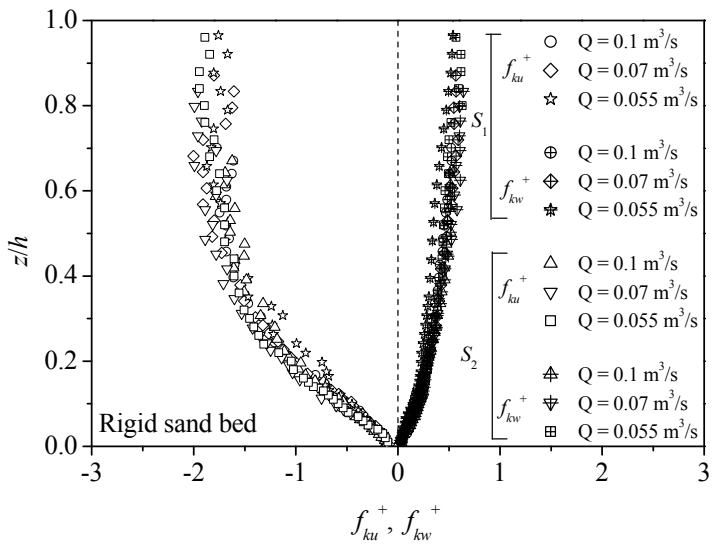

(e)

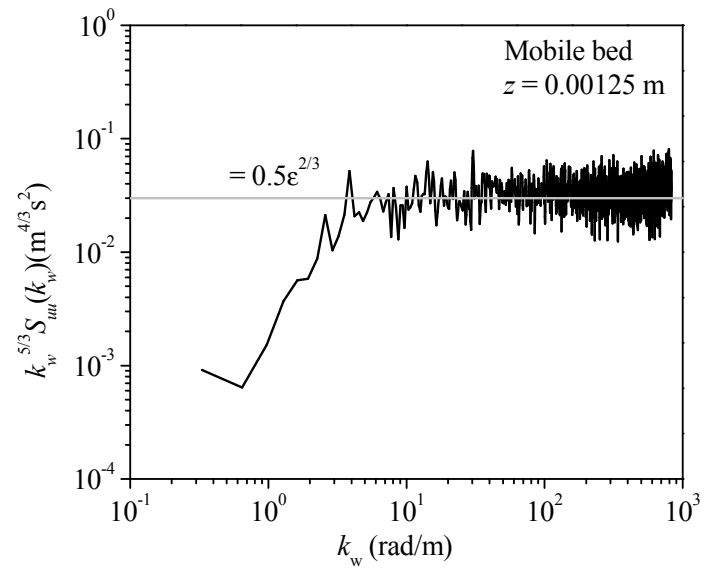

(b)

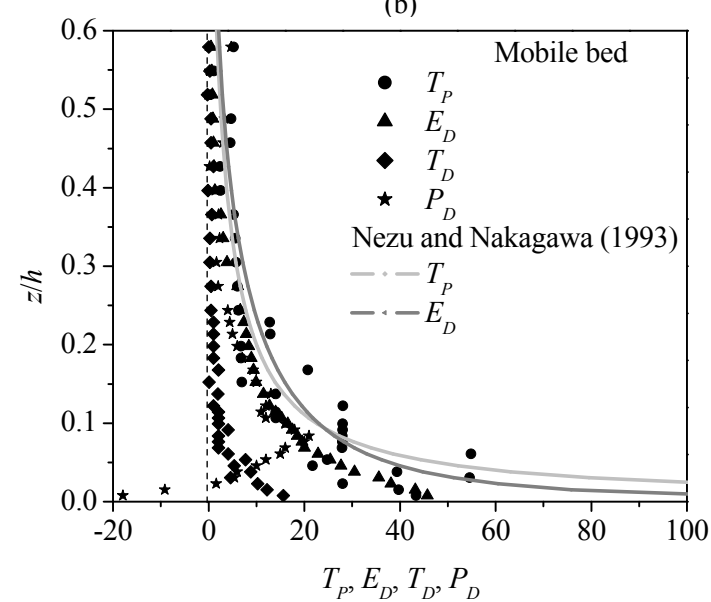

(d)

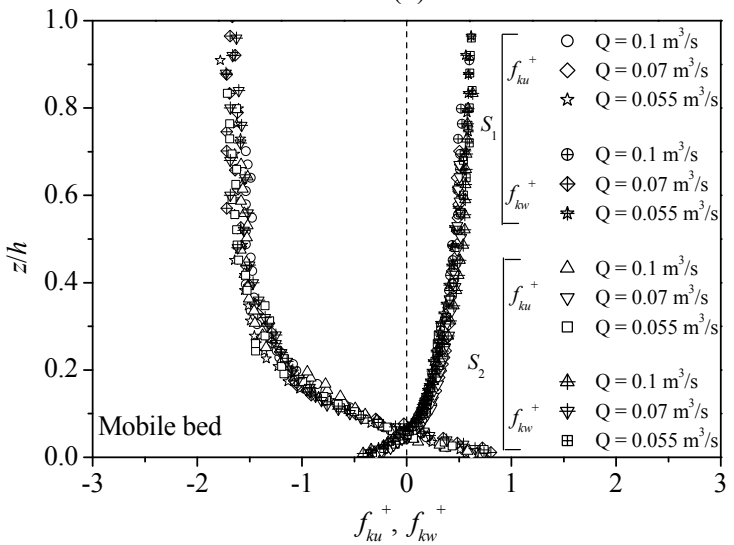

(f)

Fig. 10. (a, b) TKE dissipation rate, (c, d) TKE budget components and (e, f) TKE flux assessment for rigid sand bed and mobile-bed.

\section{Relative role of sediment mobility on turbulent kinetic energy (TKE) balance:}

The results presented in the earlier sections revealed nearbed damping of RSS aliquot resulting lower value of $u^{*} \tau$ in the mobile-bed tests (Table 1). Further, we attempt to analyse the issue in the tune of TKE-budget concept. In particular, the sediment entrainment as bed load transport is associated to the momentum extracted from the flow and this section demonstrate the improved description of TKE-budget in the frameworks of higher order turbulent statistics. For uniform flow conditions, the TKE-budget is expressed as, $t_{P}=\left(t_{D}+p_{D}+\varepsilon-v_{D}\right)$ (Nezu and Nakagawa, 1993) where, $t_{P}$ $=\mathrm{TKE}$-production rate, $t_{D}=\mathrm{TKE}$-diffusion rate, $p_{D}=$ pressure energy diffusion rate, $\varepsilon=$ TKE-dissipation rate, $v_{D}=$ viscous diffusion rate. The viscous diffusion rate $v_{D}$ is not considered because of large flow Reynolds numbers. Therefore, the pressure energy diffusion rate is obtained as $p_{D}=t_{P}-\varepsilon-t_{D}$. In order to resolve $\varepsilon$ satisfactorily, the inertial subrange of the velocity power spectrum, $S_{u u}\left(k_{w}\right)$ is fitted with the theoretical slope, i.e., the Kolmogorov, $-5 / 3$ curve and expressed as

$$
S_{u u}\left(k_{w}\right)=\omega \varepsilon^{\frac{2}{3}} k_{w}^{\frac{-5}{3}}
$$

where, $k_{w}$ is the radian wave number and $\omega$ is an empirical constant, which is set to 0.5 (Monin and Yaglom, 2007). Traditionally, the wave number spectrum $S_{u u}\left(k_{w}\right)$ is transformed to the frequency spectrum $S_{u u}(f)$ and $\varepsilon$ is computed as 


$$
S_{u u}(f)=\left(\frac{\bar{u}_{i}}{2 \pi}\right)^{\frac{2}{3}} \omega \varepsilon^{\frac{2}{3}} f^{\frac{-5}{3}}
$$

Figure $10 \mathrm{a}, \mathrm{b}$ presents the average value of $\varepsilon$ computed from Eq. (8) at $z=0.00125 \mathrm{~m}$ for both immobile and mobile beds. Other nondimensional TKE-budget components are estimated over the mobile and rigid sand beds for $Q=0.1 \mathrm{~m}^{3} / \mathrm{s}$ and shown in Fig. 10c, d. The nondimensional TKE-production rate $\left(T_{P}\right)$ in both the cases depict near-bed enhancement. Data plots of nondimensional TKE-dissipation rate $\left(E_{D}\right)$ shows similar trend of the $T_{P}$ profile with distinct lag in the distributions. Both the $T_{P}$ and $E_{D}$ profiles are compared with the theoretical curves (Nezu and Nakagawa, 1993) expressed as:

$T_{P}=\kappa^{-1}\left(\frac{1-z / h}{z / h}\right)$

$$
E_{D}=\frac{9.8}{(z / h)^{0.5}} \exp (-3 z / h)
$$

Nevertheless, the $T_{P}$ and $E_{D}$ obtained from Eqs. (9) and (10) overestimate the results of present study. The influence of sediment mobility is apparent in the near bed distributions of $T_{P}$ and $E_{D}$, where a markedly reduced lag is observed. In the nearbed flow zone, the $T_{P}$ reduction in mobile sand bed is attributed to the damping in RSS distributions and the difference of $T_{P}$ and $E_{D}$ at each vertical distance are compensated by the combined effect of nondimensional TKE-diffusion rate $\left(T_{D}\right)$ and pressure energy diffusion rate $\left(P_{D}\right)$. The results has an implication to influence $T_{D}$ in presence of bed load by augmenting it with respect to the immobile bed conditions, whereas, $P_{D}$ is noticed almost equal to $E_{D}$. In mobile-bed runs, the near-bed distributions of $P_{D}$ is estimated by the action of bed-load transport with a negative value $\left(P_{D}=-12\right)$, which offers an evidence of increasing turbulence production which is well in conformity to the Detert et al. (2010). Further, the phenomenon can be well represented analyzing TKE flux components. The data plots in Fig. 10e, f present the vertical distributions of dimensionless longitudinal and vertical TKE-flux components. In case of immobile sand bed under clear water condition, the TKE-flux for longitudinal velocity component, $F_{k u}\left(=f_{k u} / u^{3}\right)$ depicted negative value with a positive transport of vertical TKE-flux, $F_{k w}\left(=f_{k w} / u^{*}\right)$ throughout the flow depth. This has an agreement on $F_{k u}$ transports against the longitudinal direction of flow due to the higher frictional resistance induced by the inertia of flowing fluid layer in rigid sand bed. On the contrary, the influence of bed load transport under mobile bed conditions depicted longitudinal and downward transports of TKE-flux components indicating positive $F_{k u}$ and the negative $F_{k w}$ responsible to induce an accelerating effect in the near-bed flow zone.

\section{CONCLUSIONS}

The influence of sediment entrainment in flows as bed-load transport on the log-law parameters that express the velocity distributions has been studied experimentally and compared with those in rigid sand bed under clear-water conditions. The instantaneous velocities in flows were measured by an acoustic Doppler velocimeter. Experimental findings are discussed and summarised below:

1. Sediment entrainment in flows changes the parameters of the logarithmic law: the von Kármán coefficient $(\kappa)$ decreases, whereas the virtual bed and the zero-velocity levels $\left(z_{0}\right)$ in- crease. The frictional velocity $\left(u^{*}\right)$ decreases indicating a reduction of flow resistance.

2 . The streamwise velocity profile with $z_{0}$ set from regression analysis and $\kappa$ from mixing length theory offers best fittings to the log-law of the wall.

3. The universal value of $\kappa$ allows a better fitting of the streamwise velocity profile over immobile bed only whereas; the log-law of the wall in presence of bed-load is characterized by a decrease in $\kappa$.

4. A reduction in RSS distributions in presence of bed-load is associated with the extraction of momentum from the main flow to maintain grain motion overcoming the bed resistance resulting an excessive near-bed damping and reduction in $u^{*}$.

5. The influence of sediment entrainment on the TKE-budget is noticeable inducing the pressure energy diffusion rate to negative magnitude in the near-bed flow zone. Moreover, in the near-bed flow zone, sediment entrainment as bed load is associated with a positive streamwise and a negative vertical TKEflux, respectively.

The aforementioned results offer to solve number of issues on mobile bed hydraulics as a future research aim. The bed shear stress computed from the bed slope in presence of bedload is disadvantageous. Hence, our results permit to elaborate carefully the reduction of RSS in presence of bed-load. Moreover, the log-law of wall in mobile-bed streams and its application with traditional $\kappa$ is strongly doubtful owing to the reduced value in mobile bed. The TKE budget analysis reveals near-bed negative pressure energy diffusion rate indicating of lowpressure field which offer significant impetus on the future scope of research towards sediment dynamics in mobile bed flows. Nevertheless, the present study offers how best to consider the turbulent production and energy dissipation events into a theoretical model describing the sediment transport phenomenon as future scope of research.

\section{REFERENCES}

Balachandar, R., Blakely, D., Tachie, M., Putz, G., 2001. A study on turbulent boundary layers on a smooth flat plate in an open channel. J. Fluid Eng.-T ASME, 123, 394-400.

Balachandar, R., Bhuiyan, F., 2007. Higher-order moments of velocity fluctuations in an open channel flow with large bottom roughness. J. Hydraul. Eng., 133, 77-87.

Best, J., Bennett, S., Bridge, J., Leeder, M., 1997. Turbulence modulation and particle velocities over flat sand beds at low transport rates. J. Hydraul. Eng., 123, 1118-1129.

Calomino, F., Gaudio, R., Miglio, A. 2004. Effect of bed-load concentration on friction factor in narrow channels. In: Proc. of the Second Int. Conf. on Fluvial Hydraulics, River Flow 2004, Taylor and Francis, London, U.K., (1), pp. 279-285.

Carbonneau, P.E., Bergeron, N.E., 2000. The effect of bedload transport on mean and turbulent flow properties. Geomorph., 35, 3-4, 267-278.

Detert, M., Weitbrecht, V., Jinka, G.H., 2010. Laboratory measurements on turbulent pressure fluctuations in and above gravel beds. J. Hydraul. Eng., 136, 779-789.

Dey, S., Raikar, R.V., 2007. Characteristics of loose rough boundary streams at near-threshold. J. Hydraul. Eng., 133, 288-304.

Dey, S., Das, R., Gaudio, R., Bose, S.K., 2012. Turbulence in Mobile-Bed Streams. Acta Geophysica (Institute of Geophysics, Polish Academy of Sciences), 60, 1547-1588.

Ferreira, R.M.L., Franca, M.J., Leal, J.G.A.B., Cardoso, A.H., 2012. Flow over rough mobile beds: Friction factor and vertical distribution of the longitudinal mean velocity. Water 
Resour. Res., 48, W05529. DOI: 10.1029/2011WR011126

Gaudio, R., Miglio, A., Dey, S., 2010. Non universality of von Kármán's $\kappa$ in fluvial streams. J. Hydraul. Res., 48, 658663.

Gaudio, R., Miglio, A., Calomino, F., 2011. Friction factor and von Kármán's $\kappa$ in open channels with bed-load. J. Hydraul. Res., 49, 239-247.

Goring, D.G., Nikora, V.I., 2002. Despiking acoustic Doppler velocimeter data. J. Hydraul. Eng., 128,117-126.

Grass, A.J., 1970. Initial instability of fine bed sand. J. Hydraul. Div., 96, 619-632.

Guo, J., 1998. Turbulent velocity profiles in clear water and sediment-laden flows, PhD Thesis. Colorado State University, Fort Collins, CO.

Gust, G., Southard, J.B., 1983. Effects of weak bed load on the universal law of the wall. J. Geophys. Res., 88, 5939-5952.

Kaji, A.M.H., 2013. Turbulent Structure in Open Channel Flow. Electronic Theses and Dissertations. 4887. https://scholar.uwindsor.ca/etd

Kirkgoz, M.S., Ardiclioglu, M., 1997. Velocity profiles of developing and developed open channel flow. J Hydraul. Eng. 123, 1099-1105. https://doi.org/10.1061/(ASCE)07339 429(1997)123:12(1099).

Kironoto, B., Graf, W.H., 1994. Turbulence characteristics in rough uniform open-channel flow. Proc. Inst. Civ. Eng. Water, Maritime and Energy, 106, 333-344. https://doi.org/10.1680/iwtme .1994.27234.

Malakar, P., Datta, A., Das, R., 2020. Influence of weak bedload transport on mean flow characteristics over immobile smooth bed surface under dynamic equilibrium flow conditions. Water Res. Mangm., 34, 4959-4973. https://doi.org/10.1007/s11269-020-02702-5

Mignot, E., Barthelemy, E., Hurther, D., 2009. Doubleaveraging analysis and local flow characterization of nearbed turbulence in gravel-bed channel flows. J. Fluid Mech., 618, 279-303.

Miguntanna, N.S., Moses, H., Sivakumar, M., Yang, S.-Q., Enever, K.J., Riaz, M.Z.B., 2020. Re-examining log law velocity profile in smooth open channel flows. Env. Fluid Mech., 20, 953-986. https://doi.org/10.1007/s10652-01909733-6
Monin, A.S., Yaglom, A.M., 2007. Statistical Fluid Mechanics. Vol. II: Mechanics of Turbulence. Dover Publications, New York, USA.

Nezu, I., Nakagawa, H., 1993. Turbulence in Open-Channel Flows. Balkema, Rotterdam, The Netherlands.

Nikora, V.I., Goring, D., 2000. Flow turbulence over fixed and weakly mobile gravel beds. J. Hydraul. Eng., 126, 679-690.

Nikora, V., Koll, K., McLean, S., Dittrich, A., Aberle, J., 2002. Zero-plane displacement for rough-bed open-channel flows. In: Proc. Int. Conf. on Fluvial Hydraulics, River Flow 2002, Louvain-la-Neuve, Belgium, pp. 83-92.

Owen, P.R., 1964. Saltation of uniform grains in air. J. Fluid Mech., 20, 225-242.

Raupach, M.R., Shaw, R.H., 1982. Averaging procedures for flow within vegetation canopies. Boundary-Layer Meteorol., 22, 79-90.

Schlichting, H., Gersten, K., 1979. Boundary-Layer Theory. Springer, Berlin/Heidelberg, Germany.

Smith, J.D., McLean, S.R., 1977. Spatially averaged flow over a wavy surface. J. Geophys. Res.: Oceans, 82, 12, 17351746.

Song, T., Graf, W.H., Lemmin, U., 1994. Uniform flow in open channels with movable gravel bed. J. Hydraul. Res., 32, 861-876.

Song, T., Chiew, Y.M., Chin, C.O., 1998. Effect of bed-load movement on flow friction factor. J. Hydraul. Eng., 124, $165-175$.

Van Rijn, L.C., 1984. Sediment transport, part I: bed-load transport. J. Hydraul. Eng., 110, 1431-1456.

Wang, Z., Larsen, P., 1994. Turbulent structure of water and clay suspensions with bed load. J. Hydraul. Eng., 120, 5, 577-600.

Yang, S.Q., 2010. Depth-averaged shear stress and velocity in open-channel flows. J. Hydraul. Eng. ASCE., 136, 11. https://doi.org/10.1061/(asce)hy.1943-7900.00002 71.

Yeganeh-Bakhtiary, A., Shabani, B., Gotoh, H., Wang, S.S.Y., 2009. A three-dimensional distinct element model for bedload transport. J. Hydraul. Res., 47, 203-212.

Received 5 March 2021 Accepted 22 June 2021 